\title{
A population ecology perspective on the functioning and future of health information organizations
}

Running head: Population ecology of health information organizations

Vest, Joshua R.; Menachemi, Nir

\section{ABSTRACT}

Background: Increasingly, heath care providers need to exchange information to meet policy expectations and business needs. A variety of health information organizations provide services to facilitate health information exchange. However, the future of these organizations is unclear.

Purpose: This study uses population ecology theory to explore the environmental context, potential futures, and survivability of community health information organizations (HIOs), enterprise health information exchanges (HIEs), and electronic health record (EHR) vendor-mediated exchange.

Approach: Qualitative interviews with 33 key informants representing each type of health information exchange organization were analyzed using template analysis.

Results: Community HIOs, enterprise HIEs, and EHR vendors exhibited a high degree of competition for resources, especially in the area of exchange infrastructure services. Competition resulted in closures in some areas. In response to environmental pressures, each organizational type was endeavoring to differentiate its services and unique use case, as well as pursing symbiotic relationships, or attempting resource partitioning.

Conclusion: Health information organizations compete for similar resources and are reacting to environmental pressures to better position themselves for continued survival and success. Our ecological research perspective helps move the discourse away from situation of a single exchange organization type towards a view of the broader dynamics and relationships of all organizations involved in facilitating health information exchange activities.

This is the author's manuscript of the article published in final edited form as:

Vest, J. R., \& Menachemi, N. (2017). A population ecology perspective on the functioning and future of health information organizations. Health Care Management Review. http://dx.doi.org/10.1097/HMR.0000000000000185 
Practice Implications: Health information organizations are attempting to partition the environment and differentiate services. Health information exchange options should not be construed as an "either/or" decision, but one where multiple and complementary participation may be required.

\section{INTRODUCTION}

Health care organizations are under ever increasing pressure to effectively and efficiently exchange electronic patient information with other providers. Various federal policies, including the Medicare Access and CHIP Reauthorization Act of 2015, the Meaningful Use Program, information blocking prohibitions, a commitment to value-based purchasing, and readmission penalties, all predicate the need for the exchange of electronic patient information (114th Congress, 2015; DHHS 2010; 2011). Furthermore, individual providers routinely want access to information during their patients' transitions of care; and patients expect information to be available electronically across care settings (Ancker, Edwards, Miller, \& Kaushal, 2012). Additionally, evidence suggests health information exchange supports more effective clinical care and efficient business operations (Rudin, Motala, Goldzweig, \& Shekelle, 2014).

Health Information Organizations (HIOs) have developed to satisfy heath care organizations' demand for health information exchange services. HIOs offer the technological services and information governance necessary for health information exchange to occur among providers and health care organizations (The National Alliance for HIT 2008). Currently, multiple types of HIOs exist in the marketplace and, in general, providers may choose with whom they wish to work. One type is the Community HIO, also known as "public" exchanges. Community HIOs are collaborative organizations that seek exchange information among a broad set of providers for public or 
community benefits (Adler-Milstein, McAfee, Bates, \& Jha, 2008). Alternatively, Enterprise Health Information Exchanges (HIEs) offer similar services, but confine exchange activity to a more narrowly defined network of organizations (Harris Healthcare Solutions, 2012). Whereas Community HIOs tend to be independent collaboratives, enterprise HIEs are typically owned and operated by hospitals or health systems, as a means to exchange data with a limited set of affiliated and trusted providers (Harris Healthcare Solutions, 2012). Yet still, electronic health record (EHR) vendors can act as HIOs. EHR vendors have historically offered exchange within their own customer base due to internal interoperability, but recently EHR vendors have partnered through efforts like CommonWell and Carequality to define the governance, technical specifications, and directory information necessary for information exchange between different vendors' products (CommonWell Health Alliance, 2016; The Sequoia Project, 2017).

Despite the need for health information exchange, the current operating environment for HIOs is complicated and the future is unclear. For health care providers looking for information exchange services little guidance exists. Community HIOs, Enterprise HIEs, and EHR vendor-mediated options have each taken turns as the current industry "buzzword" and changing federal policies have created an uncertain environment (Lenert, Sundwall, \& Lenert, 2012). Further, policy makers have scathingly questioned the long-term viability of HIOs supported by public funding (Thune, Alexander, Roberts, Burr, \& Enzi, 2015) and the EHR vendor-mediated exchange option has been labeled as too insular (ONC 2015). Even expectations vary on what services and roles HIOs should assume (JASON , 2014). Importantly, cost remains a barrier to participation for many providers and the return on investment from participation may be difficult to quantify.

The information exchange services of HIOs are critical to the nation's objectives regarding cost and quality improvement (ONC 2011). However, these policy objectives exist within an undoubtedly changing landscape. Providers' need to exchange information will continue, but the rate at which 
information technology innovations occur is too rapid, the health policy environment too uncertain, and the challenges facing organizations too great for HIOs not to adapt to market pressures. But, what will that future be? Specifically, does the current environment favor a particular type of organization? Are some HIOs better positioned compete for resources than others? If so, how can organizations best align their activities to meet the challenges of this environment? To explore what the future may hold, we adopt a population ecology perspective as a theoretical lens from which to explore questions of $\mathrm{HIO}$ activities and survivability.

\section{THEORETICAL FRAMEWORK}

Population ecology draws on biological models and concepts to explain the dynamics, and ultimately survivability, of a group of similar organizations within the environment (Hannan \& Freeman, 1977). Specifically, the extent of competition between organizations for finite resources, each organizations' capabilities, and changes to the institutional environment combine to define the "range of conditions" (i.e. the niche) in which a population of organizations can survive (Popielarz \& Neal, 2007). Organizational fit, or lack thereof, within these environment constraints in turn selects organizations for survival or adaptation (Betton \& Dess, 1985). Multiple concepts and processes outlined by population ecology appear in the history, events, and features of HIOs, indicating the theory is a useful lens from which to view current dynamics, and to consider future developments, in $\mathrm{HIO}$ activity.

First, a population ecology perspective creates advantages by moving research and policy implications away from a focus on a single HIO type towards a view of the broader dynamics and relationships of all organizations involved in health information exchange. Existing research on HIOs has generally studied the different types of HIOs independently (e.g. Adler-Milstein et al., 2008), even though community HIOs, enterprise HIEs, and EHR vendor-mediated exchanges all fit within the label of HIOs (The National Alliance for HIT 2008), all are interacting, and competing, 
within the environment (Miller 2012; NORC, 2016), and all transform similar inputs into similar outputs (i.e. share a common "blueprint") (Hannan \& Freeman, 1977). Viewing these multiple organizational types as a single "species" increases the comprehensiveness of research and better reflects the actual composition of the environment. Also, within species variations in terms of different features or characteristics is a key area to explore as these variations play important roles in organizational survivability (Astley, 1985). Better insight into the variation between HIO types, helps refine our understanding of competition, and potential cooperation.

Second, due to the focus on organizational survival alone, population ecology is a reasonable vantage point from which to explore questions about the future viability of HIOs. Specifically, evidence suggests HIOs follow population ecology's density-dependent curve of organizational survival. In this process, the organizational population grows (i.e. new foundings) to its peak size, competition for resources increases, reducing the foundation of new organizations and increasing the mortality of existing population members (Carroll \& Hannan, 2003). No complete census of current and previous HIOs exists, but qualitative, survey, and popular media reporting suggest US HIOs mimicked a density-dependent pattern. Community HIOs have roots in the "experiments" with information sharing in the 1990s spurred on by the growing promise of the Internet, of which many of these failed (Miller \& Miller 2007). The previous decade witnessed the peak popularity of community HIOs with several hundred in existence (Adler-Milstein et al., 2008). After this peak, organizational mortality appeared to rise and current estimates indicate that approximately 125 community HIOs are in operation (Adler-Milstein, Lin, \& Jha, 2016). Additionally, ,the conceptual shift in the early 2000s from the siloed information systems of electronic medical records to the information accessible, interoperable EHR model, propelled EHR vendors into the business of moving information. Concurrent, with this shift was an increase in vendors in the marketplace. Overtime the market has consolidated and numerous EHR vendors have gone out of business 
(Leventhal, 2017). While the data are even sparser, trade reports and some research indicated that the enterprise HIE approach has also grown rapidly (Harris Healthcare Solutions, 2012). This difference in trajectories within the population of HIOs (described in detail by Lenert et al., 2012; Rubin, 2003; Vest \& Gamm, 2010) suggests the possibility of selection forces at work.

Nonetheless, survival is not the sole outcome of interest. Population ecology allows for individual organizations to evolve, adapt, and even cooperate in response to environmental pressures overtime (Singh \& Lumsden, 1990). HIOs have changed over time to meet the expectations of the environment (Vest \& Gamm, 2010) and have created partnerships in attempts to position themselves within the market for information exchange service (see, for the most recent example, the cooperation between Carequality and CommonWell). Additionally, some changes to HIOs are isomorphic, suggesting the action of institutional pressures in the environment. For community HIOs, tracking surveys and national evaluations reveal that service offerings, exchange partners, and technological approaches are fairly similar (NORC, 2016). For all HIOs, some instances of isomorphism may be attributable to policy e.g. community HIOs, enterprise HIEs, and EHR vendors all offer DIRECT messaging services.

Lastly, HIOs operate in a shared and limited space. The importance of competition for limited resources in survival is evidenced, or least inferred, by resulting closures or mergers when multiple HIOs attempted to offer services in the same markets (see for example Robinson, 2007). Likewise, when multiple HIOs exist within a market, hospitals often only participate with one organization (Vest, 2016). Additionally, HIO leaders report that community HIOs and enterprise HIEs compete for hospital resources and attention (Vest \& Kash, 2016).

\section{METHODS}


We explored the population of HIOs through key informant interviews with organizational leaders representing diverse providers of information exchange services and relevant stakeholders.

\section{Key informants}

We interviewed 33 representatives from community HIOs, health systems, EHR vendors, trade organizations, and state government from 21 different organizations in five states (see Table 1). Interviews were conducted as part of a larger project on the applications of information exchange to population health. Informants were identified with the assistance of the state hospital association, state government agencies, and trade association contacts. To be consistent with the perspectives and expectations of population ecology, we specifically sought informants from all types of HIOs including from organizations that had not "survived." Key informants represented a recently merged community $\mathrm{HIO}$, a recently closed community $\mathrm{HIO}$, a newly founded community $\mathrm{HIO}$, health systems with and without enterprise HIE, and the EHR and health information exchange technology vendor community. Key informants represented leadership and strategy setting positions with titles like Chief Executive Officer (CEO), President, Director of Population Health, Director of Informatics, Chief Medical Officer, Vice President (VP), or Chief Financial Officer (CFO).

Interviewing followed a semi-structured format with open-ended questions, were conducted onsite or by phone, and lasted an average of 45 minutes. The interview guide covered questions suggested by the population ecology perspective about organizational foundation, the current operating environment, resources, perceptions on the different types of organizations, closures, competition, and future expectations. Interviews were recorded with consent for transcription. The project was approved by the Indiana University Institutional Review Board. Analyses

Because our interviews we were guided by a well-defined theoretical framework with wellspecified constructs, we used a template analytical approach (King, 1998). Template analysis an 
approach to qualitative data analysis that applies an a priori set of hierarchical codes, as in content analysis. However, template analysis allows for coding scheme revision by adding new codes and the revisiting the relationships among codes over the course of analysis, as in grounded theory. The initial template was based on constructs from population ecology theory and observations from field notes. The template (Table 2) was refined through a preliminary reading of interview transcripts. The final coding scheme was applied to all transcripts. Finally, we identified relationships between themes based on co-occurrence within the data and by stratifying themes according to organization type. These connections across themes and organizational type were used in niche definition, to describe within niche dynamics between organization types, and to identify responses to the environment.

\section{RESULTS}

\section{Defining niche by exchange services}

Each type of HIO provided the exchange infrastructure (Table 2) necessary to move patient information between organizations, i.e. each offered to be the "plumbing" and "connections" or the “intermediary" between exchange partners. HIOs' array of services extended to other areas, but this core exchange infrastructure was common to all (Figure 1). Historically, community HIOs were the first to offer such an exchange infrastructure, and a community HIO summarized its importance thusly: "The core of our business...is results delivery. And it's nothing sexy or fancy at all, it's simply get me all your clinical results and I'll deliver them to doctors." Another described it as: "You send us your information and then we take care of routing it and getting it where it needs to go." However, as a trade association representative observed, "You can claim to have interoperability with a lot of different things...[and]... If you're gonna make a decision based on the short-term optimization of your organization's output, then you basically go with the cheapest thing that you spend the least time on." He was referencing EHR vendor-mediated exchange as the lower-cost 
alternative. A vendor noted, "CommonWell and Carequality [EHR vendor mediated networks] are ... offering essentially free, cheap interconnectivity.” Likewise, a health system leveraging an EHR as their enterprise HIE solution reported, "Exchanging information within Epic is less than pennies."

A community $\mathrm{HIO}$ pointed to changes and disruptions in the policy environment (particularly federal policies) as the root cause for all HIOs operating within this niche dimension: "Meaningful Use and certification determined that every certified EHR had to be able to export a continuity of care document. With that, the EHRs began to think that they should be responsible for the sharing of data rather than a [community HIO]." A state government official concurred that Meaningful Use's "lite HIE requirements" introduced EHR vendors into this space. For health care systems, costs were critical when choosing between community HIOs and EHR vendors for exchange services, but the most important factor for those opting for enterprise HIEs was the participants in exchange. Entities with enterprise HIEs focused on the connections "within our EMRs", "our medical network", "partners who share risk", and "our members". A health system’s HIE program manager created the connection between technology and strategy by clearly articulating for whom services were intended: "In order to participate in our HIE, you have to be a member of our [network]. We aren't trying to be an HIE for the public."

\section{Defining niche by needed resources}

All HIO types were dependent on the environment for key resources, the most important of which was customers (or participants as a source of financing). Simply, everybody "needs money." As a community HIO noted, "to house and run a central data repository, build those interfaces, market to services, all of the things it takes to put an HIE together needs a certain amount of money." Also, a large number of participants were critical to an HIO's functionality and value. A trade association representative summarized it as "one of the essential pieces is having a critical mass of the stakeholders in the service area." A vendor also stressed the importance of a "critical mass", 
because "...having enough data sources connected that...[providers] are going to find information of value often enough..." Likewise, a health system noted the importance of connecting affiliated providers to their enterprise HIE so that "they have a more robust clinical history of what's been going on with their patient and can use that information at the point of care for decision making." Nonetheless, all participants are not equal. "Data is becoming a commodity", so all types of HIOs prioritized "clinics and hospitals because they're gonna be your clinically-rich patient documents and patient transactions." The focus on large data providers concerned community HIOs that mental health providers, social service providers, public health agencies, and small hospitals may be left out of exchange activities. Moreover, customers, themselves, could act like a limited resource by participating with only one HIO type.

Additionally, trust, public funding, and technology vendors emerged as resources sought by community HIOs. As collaborative, multi-stakeholder endeavors, community HIOs relied on participants to be willing, engaged, and supportive partners. Conversely, lack of trust among participants (frequently occurring in markets with much competition) was sighted as a reason for two community HIOs' failures. Trust was something community HIOs had to actively cultivate through relationship building. In contrast, EHR vendors and health systems with enterprise HIEs were not endeavoring to build trust among diverse, competing stakeholders. Public funding was another resource specific to community HIOs. Public funding, in the form of grants, was met with skepticism by multiple respondents. A vendor commented, "The first wave put themselves on the map using grant funding. As soon as the grant funding dried up, many of these [community HIOs] either completely went away or very quickly became all but obsolete." Similarly, a community HIO observed, "There are federal grants and programs from time to time, but obviously that's not something you would want to count on for sustainability." A third resource, health information exchange technology vendors, was also important to community HIOs. Community HIOs 
competed among themselves for vendors' attention, and a trade association representative reported how a vendor going out of business further complicated a metropolitan area's effort at exchange, and a vendor caused another community $\mathrm{HIO}$ to rapidly alter plans. However, reliance on a information exchange technology vendor was not limited to community HIOs, health systems with enterprise HIEs also had to select technology partners.

\section{Competition between organizations for resources}

When asked if community HIOs, enterprise HIEs, and EHR vendors were in competition, responses ranged from emphatic assertions, like “...(t)here's competition everywhere from everybody..." and "...(t)hey're absolutely in competition...", to the more muted "...not in direct competition..." or "...not in true competition..." More direct evidence of competition was in the reports of potential customers choosing one HIO type over another. A recently closed community HIO reported on the perceived substitutability with EHRs mediated exchange: "Epic [EHR vendor] was ensconced in the cities where $80 \%$ of the population had an Epic record, so they certainly didn't think they needed to hook up with anybody else. Ultimately, what happened is our financial ability to sustain ourselves went down the tubes and we had to close our doors." Similar comparisons existed between EHRs and enterprise HIEs; a health system with a single EHR platform reported viewing the EHR as their enterprise HIE solution and another health system's CIO would extend instances of their own EHR to ambulatory care practices instead of connecting participants through an enterprise HIE. Alternatively, a health system observed, "You probably don't need an [enterprise] HIE because you do have that 'query \& response' capability through [EHR vendors].” Likewise, informants from the three health systems with enterprise HIEs reported making a conscious decision away from community HIOs. As a vendor noted, "[Health systems] are not going to want to share that proprietary data [in a community HIO] with their competitors." 
Both trade association representatives also noted examples where enterprise HIEs and community HIOs had difficulty existing in the same market areas due to hospital competition.

Evidence of competition between HIOs of the same type existed as well. A community HIO noted that during the EHR adoption push following the HITECH Act, it was "high competition..., so it was go out and grab, a land grab." Another respondent recalled how a federally funded state designated entity suggested to community HIOs that "you guys can go ahead and close down. We got it". Also, if more than one community HIO viewed a hospital within their service areas, "(h)istorically, both would try to recruit and try to win that business." While community HIO respondents suggested this type of competition was more in the past, a state government official observed current competition (“... [community] HIOs are in competition with each other for their own sustainability"). Competition within the enterprise HIE type of HIO differed. One on hand the vendors offering health information exchange technology compete and increasingly compete with other technology vendors offering services around "care coordination and pop[ulation] health." Differently, however, the health systems providing enterprise HIE services are also competing with other health systems in their market. Lastly, EHR vendors are "working hard...to try and capture more customers" as well.

\section{Responses to the environment: differentiation by services}

Representatives from all types of organizations contended for the need for HIOs to move away from competing to be the sole provider exchange infrastructure for health care organizations. From the EHR vendor perspective, competition was pointless, because they were positioned to dominate: "Pretty much all the major vendors are going to support the CommonWell and Carequality style federated queries. What that means for the [community HIOs] is they need to offer some additional value or they're going to go away." The sentiment from a community HIO was not very different: “... if the only thing a [community HIO] is doing is providing plumbing, if you're just essentially an 
intermediary, you're probably going to get 'dis-intermediated' over time." A trade association representative agreed: "Successful [community HIOs] will move away from just moving data." Similarly, a health system with an enterprise HIE commented, "The HIE technology itself is not really the differentiator. It's more of: 'How is it being operationalized?' 'How is it implemented?' And are your members getting the value they expected from it?"”

How organizations sought to differentiate themselves was grounded in their self-identified_value propositions and use cases (summarized in italics within each HIO type's circle in Figure 1). For community HIOs, the value proposition was "no matter where patients showed up, you had access to the latest and greatest information” regardless of EHR (e.g. “...the capacity to exchange with any EHR...”), individual provider's level of adoption (e.g. “...the folks that don't have any EHRs...we can bridge those gaps," or "...taking the information the last mile...”), or type of organization (e.g. "competitors", "social services", "long-term care", "public health"). With the broad, collaborative perspective, community HIOs argued they were best positioned to support population health initiatives with services like admission-discharge-transfer notifications to inform providers of events outside their network, state-wide patient identity management for accountable care organization's case managers, longitudinal patient records, or to exchange with those organizations that can best address the social determinants of health like law enforcement, rehabilitation clinics, or charity providers. A community HIO summarized current trends as, "(T)he argument that people have been making for many years is, 'Epic takes care of all of my needs, I can exchange with people that I most need to exchange with.' But the transition away from fee-for-service and into performancebased contracts is really changing that discussion, because providers understand that simply moving the clinical data around does not get them the information that they need in order to be able to do the population health management." All in all, community HIOs identified a key survival strategy was beyond "just moving data", because EHR vendors do that "really, really well". Community 
HIOs need to get "into population health, data analytics, taking all this information that they're managing and finding more and better ways to abstract and provide value with it." Additionally, community HIOs were identified as supporting public health and having "larger community benefits".

Enterprise HIEs served different use cases that also required services beyond the exchange infrastructure. An integrated delivery system observed, "If you want to be able to take information in and normalize it, be able to mine it, do some analytics off of it to be able to manage the care of a population...[EHR vendor mediated exchanges] are not going to cut it. You do need extra functionality." Respondents representing the enterprise HIE perspective emphasized analytics, for example, to support care coordination for high cost patients. Also, a health system was levering enterprise HIE for centralized scheduling and order submission for both employed and affiliated providers. An enterprise HIE vendor representative drew an interesting contrast with community HIO. Both had the capability to aggregate data for analytic purposes, but from her perspective, community HIOs were "not focused on outcomes", whereas "[enterprise HIEs]...got some very specific outcomes they are trying to work towards."

On one hand, EHR mediated exchange aligned with clinical care provision, according to an EHR vendor, by supporting "direct treatment queries" with the advantage of being able to "move the data back and forth" without being "limited by community or state boundaries". The same informant went on to add, "What they [EHR vendor mediated exchange options] do not do, just to be totally clear, they do not add any value to that data. They just get it to you. So they're not going to tell you, 'Hey, there's a gap in care,' or 'You've got one doc who thinks this is migraine and one doc who thinks it's not migraine and you better figure out which it is because if it's not migraine they shouldn't be taking that dangerous migraine drug'... We don't do any of that.”

\section{Responses to the environment: cooperation}


Additional reactions to the environment included cooperation within and across organizational types. EHR vendors had been selectively cooperating on exchange activities previously for several years (i.e. one set of vendors was aligned with Carequality and another set with CommonWell). However, an EHR vendor represented described the importance of a recent change: "With the recent announcement [of] CommonWell and Carequality agreeing to collaborate, there's now a broader network...This means is that over the course of the coming year, Epic, Cerner, AllScripts, Athena, and eClinical will all be able to query each other's databases on behalf of a particular patient in a direct treatment situation." Community HIOs were cooperating too, in order to create broader exchange networks. Some cooperation was historical and on regional levels. As one community HIO observed, “[The state] has a very collaborative environment...they’ve all been exchanging data with each other for many, many years." More recently, as part of a trade association initiative, community HIOs were working to create even larger exchange networks, called the "patient centered data home". A community HIO summarized cooperation as logical, "We do, in our area, have a lot of that overlap, so it makes a lot of practical sense," and went on to comment that it was the convening nature of the trade association that supported cooperation, "SHIEC [Strategic Health Information Exchange Collaborative] kind of brought that together to say, 'Each of us know how to do HIE's successfully in our own market. How do we connect our markets in a way that makes sense and benefits the patient?"' Another community HIO echoed the benefits of cooperation, “'I think the way that we can make ourselves more commercially viable is to find ways to stitch ourselves together...Not separate contracts. Not separate data use agreements. Not separate financial components. It's one fee for all the data, and we figure it out how to do it ourselves. They just need a primary contact and then they get all the data." In addition, community HIO leaders also endeavored to cooperate with other actors. One stated, "My strategy is to really develop relationships with these EHR vendors and these so-called national exchanges like CommonWell, 
Sequoia, and so forth, and really understand what it is they do and how can we plug into them. So rather than compete, let's work together and see how we can exchange." Another shared this viewpoint: "(T)here is an opportunity to be complementary....and in a collaborative way we can both serve our own customer base...My vision for that is a hospital provider is likely going to connect out multiple networks...CommonWell...Carequality... community HIEs ...and that becomes part of the fabric because they serve different purposes." Yet another community HIO shared this belief: "[EHR vendors] need us and we need them...I feel like we have a lot to offer in areas that they don't need to focus on..." Less overt cooperation existed within the enterprise HIE space. For example, a community HIO reported exchanging data with more than one health system with an enterprise HIE, so those enterprise efforts could access more community partners. While not exactly a cooperative relationship, the enterprise HIE vendors included in this sample counted health systems, community HIOs, and EHR vendors as their customers.

\section{Responses to the environment: mortality}

Organization failures occurred in this environment and organizations merged. While respondents observed that at least one enterprise HIE vendor recently went out of business, more commonly respondents had experience with closed community HIOs, through prior jobs or from a government perspective. Reasons for closure were described in terms of lack of access to the key resources of participants and funding because "the landscape was so competitive among the health systems" (i.e. could not create trust), competition between community HIOs ("The other HIE was struggling a little bit financially, realized that there was some money on the table that we were about to get...We were literally about to sign a contract, and so they persuaded some folks to give them the money instead...Kind of put us out of business..."), or competition with enterprise HIEs and EHR vendors. Respondents were in strong agreement that over-reliance on public funding as a reason for previous community HIO failures (e.g. "The ones that have died are a lot of those that 
were funded with ARRA funding") as was being too focused only on moving information (e.g. "We've seen many of those HIEs go out of existence, right? I don't believe that 'Direct is your only solution" is a sustainable model financially, at all. That will not last"). In terms of mergers, a community HIO described the motivation for her organizations' merger in scale and skill terms. Both originally organizations were small ("She had three employees; we had nine") and each had different strengths ("We were very advanced in the technical side and not so much in quality and pop health"). Overall when asked about ongoing survivability, trade association representatives commented: "I think we'll see more industry consolidation" and "The weeding out, the survival of the fittest...do I think that's gonna continue? For sure."

\section{DISCUSSION}

HIOs compete for similar resources and are reacting to environmental pressures to better position themselves for continued survival and success. Our ecological research perspective helps move the discourse on health information exchange away from a single HIO type and towards a view of the broader dynamics and relationships of all HIOs involved in facilitating information exchange. The above results indicate clear areas of competition with potentially dominant players, areas of potential future competition, suggestions for opportunities to support comprehensive and valuable health information exchange, survival strategies, and the current challenges that limit our understanding of the environment.

The service common to all HIOs was the movement of information (e.g. "plumbing" or exchange infrastructure) and, because any of these organizational types can move information, it is simultaneously the least distinguishing feature and the point of greatest competition. Moreover, federal health policy has prioritized movement of data (114th Congress, 2015; DHHS 2010; 2011; ONC 2015) adding to importance of this capability. Given the reported low marginal costs and the 
tight integration into existing clinical workflows, EHR vendors seemed positioned to be the dominant players in this service area. By emphasizing additional services and use cases, other HIOs appear to be working towards establishing a wider range of environmental conditions in which to thrive.

Nevertheless, these efforts at differentiation suggest both areas for complementary activities and the possibility for additional competition between HIOs. Within the intersections of Figure 1 (bolded), we have identified example services that require the complementary activities of each HIO to realized quality and cost improvements. For example, patient registries support an enterprise HIE's focus on operational efficiencies and business goals (Han et al., 2016), but require the clinical data from multiple providers which may be obtained through EHR vendor mediated exchange. Conversely, the clinical documents obtained from vendor mediated exchange cannot be used for broader value without a platform for aggregation. As another example, alerts can complement the work of community HIOs and enterprise HIEs by informing participating organizations when patients have been discharged or admitted to the emergency department (ONC 2013). This set of overlapping areas illustrates the potential for cooperation through complementary services and the need for health care providers to participate with multiple HIOs realize the full potential of interoperability.

Moving towards each organization's broader conceptions of their roles (the outer rim of Figure 1), however, highlights the potential for additional instances of competition. As an example, both EHR vendor mediated exchange options and community HIOs have broad, or even nationwide, exchange aspirations (CommonWell Health Alliance, 2016; Strategic Health Information Exchange Collaborative, 2015; The Sequoia Project, 2017), which again blurs the distinction between the efforts. Also, enterprise HIEs and EHR vendor mediated options represent the "single vendor vs. best of breed" debate (Ford, Menachemi, Huerta, \& Yu, 2010), i.e. is it better to have a single or 
multiple EHRs? This dynamic occurred in our study when a health system viewed its single EHR as its enterprise HIE solution. Furthermore, the trends towards single, enterprise EHR adoption coupled with EHR vendors' increased offering of their own population health tools suggests enterprise HIE vendors and EHR vendors may move towards greater competition. Lastly, both the community HIO and the enterprise HIE respondents saw aggregation, analytics, and population health as their services. While the two differ in terms of participants, that difference may be lost, or of less consequence, to potential customers.

In addition to competition for common resources, we observed other themes and factors confirming the utility of population ecology as a theoretical framework for studying HIOs. For example, key informants suggested density dependent mortality operated in some markets, viewed those organizations with limited (or incorrectly focused) business lines were not sufficiently fit to survive, reported developing cooperative relationships (Astley \& Fombrun, 1983), and attempted at resource partitioning (Carroll, 1985). However, a fuller consideration of the population ecology perspective highlights remaining unanswered questions such as the nature environmental change (i.e. fine or coarse grained), direct measurement of organizational fitness, or the identification organizations as generalist or specialists.

Most importantly, our study does not clearly resolve the critical conceptual issue of whether or not community HIOs, enterprise HIEs, and EHR vendor mediated exchanges options are truly the same species of organization. Consistent with a single species viewpoint, our set of organizations shared similar core technologies, skills, and targeted clients. Additionally, organizations could be considered as "genetically related" (Betton \& Dess, 1985) due to mergers, common technology vendors, or shared leadership (multiple key informants reported having worked at other types of HIOs, before their current position). On the other hand, stated goals could vary among groups (e.g. widespread versus targeted exchange participation) as well as organizational control and structuring 
(Hannan \& Freeman, 1984). Species definition is a longstanding challenge within population ecology (see Young, 1988) and these findings call for at least a better taxonomy of the organizations facilitating health information exchange. A better classification of organizations would have theoretical advantages for measurement or potentially re-conceptualizing environmental dynamics in a community ecology framework. Also, a better understanding of the actors involved is critical to informing the policy environment. For example, much of federal policy has been technology focused (e.g. Meaningful Use or the National Health Information Network), which favored some organizations to the detriment of others (Lenert et al., 2012). A better classification could define the set of organizations affected by policy decisions, help anticipate any potential consequences in market structure or competition, and better assess if the options for information exchange in the US are sufficient to meet national cost, quality and safety goals.

\section{PRACTICE IMPLICATIONS}

HIOs may be attempting to partition the environment and differentiate services to their own satisfaction; however, it does not immediately follow that potential customers will realize those differences. Primarily, the responsibility falls to the managers of HIOs to ensure potential customers are clear that information exchange decisions are not an "either/or" decision, but one where multiple and complementary participation may be required. Similarly, all HIOs types have historically treated health care organizations, and especially hospitals, as finite resources: community HIOs sought to secure participation within their geography, EHR vendors seek to be "the single solution", and enterprise HIEs cast themselves as alternatives to other HIOs. Managers of health care organizations should realize such a perspective many not best serve their own organization's needs and best interests, but that more than one HIO, or an HIO that cooperates with other HIOs, may be necessary to ensure access to robust and comprehensive patient information. Nonetheless, in this current environment, managers should be prepared for continued competition because HIOs 
still overlap in terms of self-reported use cases and boarder goals. For community HIOs, in particular, survivability may be through increased size, moving towards a niche defined by population health and analytics, moving away from being the sole providers of "plumbing", which creates the most direct competition with EHR vendors.

\section{Limitations}

Findings may be limited in terms of generalizability. We interviewed multiple organizations from multiple states, and individuals with nationwide perspectives, but environmental dynamics may be different in locations where we did not recruit key informants. Also, we may have failed to identify additional key themes and important issued due to our predetermined theoretical perspective and template analysis approach. We did attempt to mitigate these limitations by using a semi-structured interview guide and by allowing for the identification of emergent themes during analysis. Additionally, we are limited by the timeframe of our study design. We were unable observe the founding of organizations or mortality or changes to the environment. Also, interoperable health information exchange is a relatively new development with more changes to the environment likely in the future.

\section{CONCLUSION}

Health care organizations have multiple options to meet their needs for effective and efficient health information exchange services. Community HIOs, enterprise HIEs, and EHR vendors have been competitors within this environment, but evidence suggest these organizations are attempting to differentiate themselves for better survivability.

\section{REFERENCES}

114th Congress. (2015). Medicare Access and CHIP Reauthorization Act of 2015.

Adler-Milstein, J., Lin, S. C., \& Jha, A. K. (2016). The Number Of Health Information Exchange

Efforts Is Declining, Leaving The Viability Of Broad Clinical Data Exchange Uncertain. Health 
Affairs (Project Hope), 35(7), 1278-85. http://doi.org/10.1377/hlthaff.2015.1439

Adler-Milstein, J., McAfee, A. P., Bates, D. W., \& Jha, A. K. (2008). The State Of Regional Health Information Organizations: Current Activities And Financing. Health Aff, 27(1), w60-69. http://doi.org/10.1377/hlthaff.27.1.w60

Ancker, J. S., Edwards, A. M., Miller, M. C., \& Kaushal, R. (2012). Consumer perceptions of electronic health information exchange. American Journal of Preventive Medicine, 43(1), 76-80. http://doi.org/10.1016/j.amepre.2012.02.027

Astley, W. G. (1985). The Two Ecologies: Population and Community Perspectives on Organizational Evolution. Administrative Science Quarterly, 30(2), 224-241. http://doi.org/10.2307/2393106

Astley, W. G., \& Fombrun, C. J. (1983). Collective Strategy: Social Ecology of Organizational Environments. The Academy of Management Review, 8(4), 576-587.

Betton, J., \& Dess, G. G. (1985). The Application of Population Ecology Models to the Study of Organizations. The Academy of Management Review, 10(4), 750-757.

Carroll, G. R. (1985). Concentration and Specialization: Dynamics of Niche Width in Populations of Organizations. American Journal of Sociology, 90(6), 1262-1283.

Carroll, G. R., \& Hannan, M. T. (2003). Density-Dependent Processes. In M. J. Handel (Ed.), The Sociology of Organizations: Classic, Contemporary and Critical Readings (pp. 254-261). London: Sage Publications.

CommonWell Health Alliance. (2016). About CommonWell Health Alliance. Retrieved February 23, 2017, from http:/ /www.commonwellalliance.org/about/

Department of Health \& Human Services. (2010). 42 CFR Parts 412, 413, 422 et al. Medicare and Medicaid Programs; Electronic Health Record Incentive Program; Final Rule. Federal Register, 75(144), 44314-44588. 
Department of Health and Human Services. (2011). 42 CFR Part 425 Medicare Program; Medicare Shared Savings Program: Accountable Care Organizations; Final Rule. Federal Register, 76(212), 67802-67990.

Ford, E. W., Menachemi, N., Huerta, T. R., \& Yu, F. (2010). Hospital IT adoption strategies associated with implementation success: implications for achieving meaningful use. Journal $O f$ Healthcare Management / American College Of Healthcare Executives, 55(3), 175-188.

Han, W., Sharman, R., Heider, A., Maloney, N., Yang, M., \& Singh, R. (2016). Impact of electronic diabetes registry "Meaningful Use" on quality of care and hospital utilization. Journal of the American Medical Informatics Association, 23(2), 242-247. http://doi.org/10.1093/jamia/ocv040

Hannan, M. T., \& Freeman, J. (1977). The Population Ecology of Organizations. American Journal of Sociology, 82(5), 929-964.

Hannan, M. T., \& Freeman, J. (1984). Structural Inertia and Organizational Change. American Sociological Review, 49(2), 149. http://doi.org/10.2307/2095567

Harris Healthcare Solutions. (2012). Harness the Power of Enterprise HIE.

JASON, the M. C. (2014). A Robust Health Data Infrastructure. Agency for Healthcare Research and Quality.

King, N. (1998). Template analysis. In G. Symon \& C. Cassell (Eds.), Qualitative methods and analysis in organizational research: A practical guide (pp. 118-134). Thousand Oaks, CA: Sage Publications Ltd.

Lenert, L., Sundwall, D., \& Lenert, M. E. (2012). Shifts in the architecture of the Nationwide Health Information Network. Journal of the American Medical Informatics Association, 19(4), 498-502. http://doi.org/10.1136/amiajnl-2011-000442

Leventhal, R. (2017). In a Top-Heavy EHR Market, Optimization Becomes the Focus. Retrieved July 13, 2017, from https://www.modmed.com/in-a-top-heavy-ehr-market-optimizationbecomes-the-focus/ 
Miller, R. (2012). Satisfying Patient-Consumer Principles For Health Information Exchange:

Evidence From California Case Studies. Health Affairs, 31(3), 537-547. http://doi.org/10.1377/hlthaff.2011.0531

Miller, R. H., \& Miller, B. S. (2007). The Santa Barbara County Care Data Exchange: what happened? Health Aff (Millwood), 26(5), w568-80.

NORC. (2016). EV ALUATION OF THE STATE HIE COOPERATIVE AGREEMENT PROGRAM: Final Report. Washington, DC.

Office of the National Coordinator for Health Information Technology. (2011). Federal Health IT Strategic Plan 2011 - 2015. Washington, DC.

Office of the National Coordinator for Health Information Technology. (2013). Improving Hospital Transitions and Care Coordination Using Automated Admission, Discharge and Transfer Alerts: a learning guide.

Office of the National Coordinator for Health Information Technology. (2015). Report to Congress: Report on Health Information Blocking. Washington DC: Department of Health and Human Services.

Popielarz, P. A., \& Neal, Z. P. (2007). The Niche as a Theoretical Tool. Annual Review of Sociology, 33(1), 65-84. http://doi.org/10.1146/annurev.soc.32.061604.123118

Robinson, B. (2007). Pennsylvania RHIO to close. Retrieved May 4, 2016, from http:/ /www.healthcareitnews.com/news/pennsylvania-rhio-close

Rubin, R. D. (2003). The Community Health Information Movement: Where it's been, where it's going. In P. W. O'Carroll, W. A. Yasnoff, M. E. Ward, L. H. Ripp, \& E. L. Martin (Eds.), Public Health Informatics \& Information Systems. New York: Springer.

Rudin, R. S., Motala, A., Goldzweig, C. L., \& Shekelle, P. G. (2014). Usage and Effect of Health Information Exchange: A Systematic Review. Annals of Internal Medicine, 161(11), 803-811. 
http:/ /doi.org/10.7326/M14-0877

Singh, J. V, \& Lumsden, C. J. (1990). Theory and Research in Organizational Ecology. Annual Review of Sociology, 16, 161-195.

Strategic Health Information Exchange Collaborative. (2015). Patient Centered Data Home.

Retrieved February 23, 2017, from http://strategichie.com/patient-centered-data-home-pcdh

The National Alliance for Health Information Technology. (2008). Report to the Office of the National Coordinator for Health Information Technology on Defining Key Health Information Technology Terms. Retrieved from http:/ /healthit.hhs.gov/portal/server.pt?open=18\&objID=848133\&parentname=Community Page\&parentid $=5 \&$ mode $=2 \&$ in_hi_userid $=10741 \&$ cached $=$ true

The Sequoia Project. (2017). What is Carequality. Retrieved February 23, 2017, from http://sequoiaproject.org/carequality/what-we-do/

Thune, J., Alexander, L., Roberts, P., Burr, R., \& Enzi, M. (2015). Where Is HITECH’s \$35 Billion Dollar Investment Going? Retrieved May 10, 2016, from http://healthaffairs.org/blog/2015/03/04/where-is-hitechs-35-billion-dollar-investmentgoing/

Vest, J. R. (2016). Geography of community health information organization activity in the United States: Implications for the effectiveness of health information exchange. Health Care Management Review. http:/ / doi.org/10.1097/HMR.0000000000000103

Vest, J. R., \& Gamm, L. D. (2010). Health information exchange: persistant challenges \& new strategies. Journal of the American Medical Informatics Association, 17(3), 288-294.

Vest, J. R., \& Kash, B. (2016). Differing strategies to meet information sharing needs: the publicly supported community health information exchange versus health systems' enterprise health information exchanges. The Milbank Quarterly, 94(1), 77-108. http://doi.org/10.1111/1468- 
0009.12180

Young, R. C. (1988). Is Population Ecology a Useful Paradigm for the Study of Organizations? American Journal of Sociology, 94(1), 1-24.

Table 1. Organizations represented by key informant interviews.

\begin{tabular}{|l|l|l|}
\hline Organization type & Number of Organizations & Number of key informants \\
\hline & $\mathrm{n}=21$ & $\mathrm{n}=33$ \\
\hline Community HIOs $^{1}$ & 7 & 13 \\
\hline Trade Associations & 2 & 2 \\
\hline Technology vendors & 4 & 4 \\
\hline Health systems & & 10 \\
\hline State government & 5 & 1 \\
\hline Payer & 1 & 3 \\
\hline
\end{tabular}

${ }^{1}$ Health information organizations

${ }^{2} 3$ of the 5 health systems interviewed reported operating an enterprise HIE

Table 2. Coding Template.

\begin{tabular}{|l|l|l|}
\hline Domain & Theme & Definition \\
\hline
\end{tabular}




\begin{tabular}{|c|c|c|}
\hline \multirow[t]{5}{*}{$\begin{array}{l}\text { Differentiating } \\
\text { dimensions }\end{array}$} & & $\begin{array}{l}\text { the characteristics and qualities that distinguish different types } \\
\text { of organizations facilitating health information exchange }\end{array}$ \\
\hline & $\begin{array}{l}\text { Exchange } \\
\text { infrastructure }\end{array}$ & $\begin{array}{l}\text { core infrastructure components (hardware, software, network } \\
\text { connectivity, etc.) supplied by the organization to facilitate } \\
\text { information exchange }\end{array}$ \\
\hline & Participants* & $\begin{array}{l}\text { types, numbers, and diversity of participants in the exchange } \\
\text { activity }\end{array}$ \\
\hline & Services & $\begin{array}{l}\text { additional services, products, or analytics offered by the } \\
\text { organization }\end{array}$ \\
\hline & $\begin{array}{l}\text { Value } \\
\text { proposition or } \\
\text { use case }\end{array}$ & $\begin{array}{l}\text { business case or how the organization's fits into health care } \\
\text { organization's needs, goals, and activities (not mutually } \\
\text { exclusive to other dimensions) }\end{array}$ \\
\hline \multirow[t]{6}{*}{ Environment } & & the organization's external operating conditions \\
\hline & $\begin{array}{l}\text { Changes \& } \\
\text { disruptions }\end{array}$ & $\begin{array}{l}\text { events (e.g. policies, innovations, etc.) that altered the } \\
\text { environment }\end{array}$ \\
\hline & Competition & organizations competing for resources \\
\hline & $\begin{array}{l}\text { Policy } \\
\text { environment* }\end{array}$ & influence of laws, regulations, and institutional actors \\
\hline & Resources & $\begin{array}{l}\text { factors required by the organization (including participants, } \\
\text { financing, trust, political will) }\end{array}$ \\
\hline & Substitutability* & $\begin{array}{l}\text { examples of how the offerings of a community HIO, enterprise } \\
\text { HIE, or EHR vendor can replace or be exchanged for the } \\
\text { offerings of one another }\end{array}$ \\
\hline
\end{tabular}




\begin{tabular}{|l|l|l|}
\hline Organizational & & changes to organizations and the composition of organizations \\
within the environment (within and between changes)
\end{tabular}

*Emergent themes identified through initial reading of transcripts. 


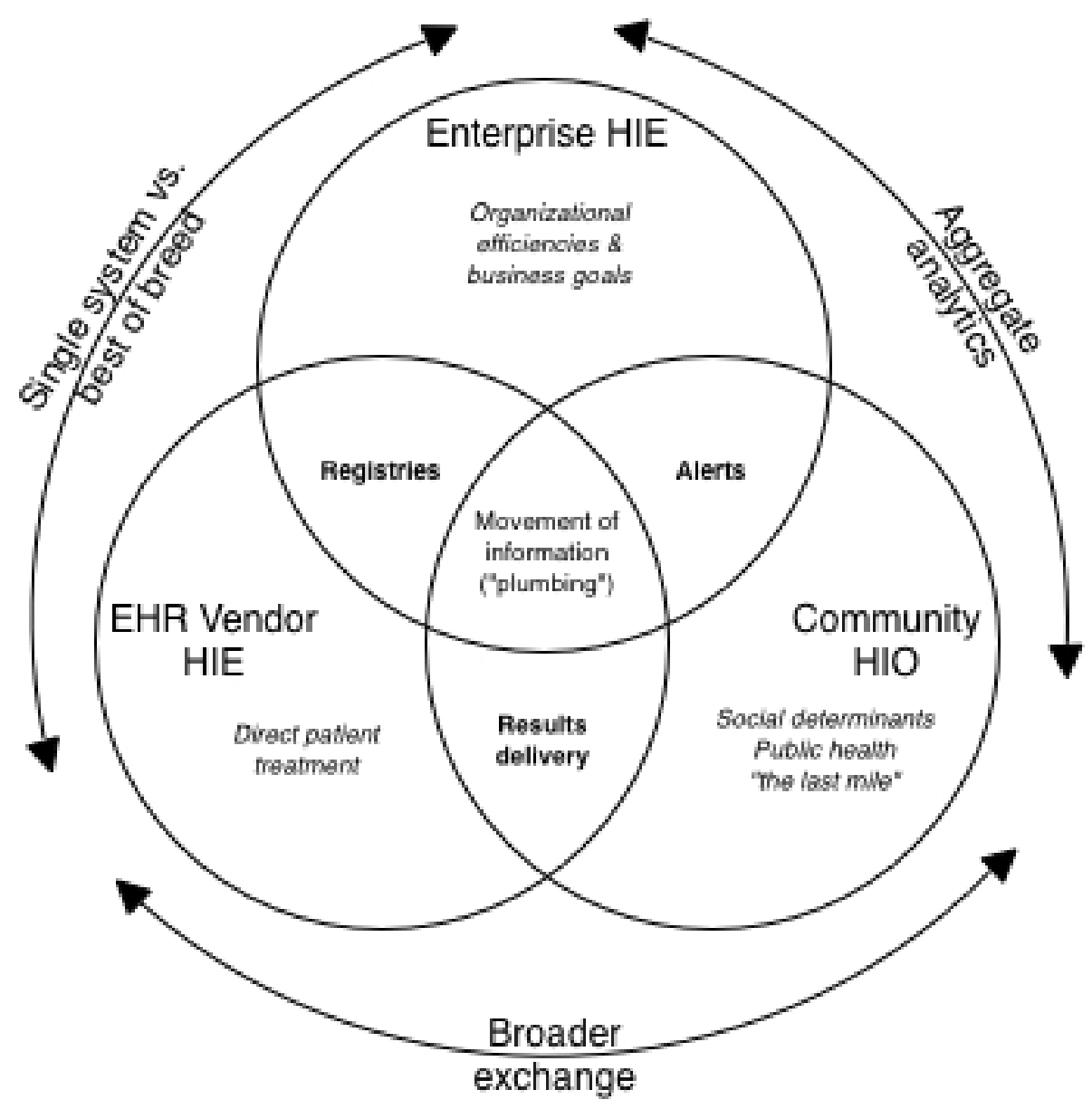

Figure 1. Representation of the types of health information organizations' array of activities within the environment. The primary of area of competition at the core, potential complementary activities in bold within intersections, unique use cases in italics, and the direction of broad roles (outer rim) to which each type is progressing. 